\title{
STRUCTURES AND DESIGN PHASE I SUMMARY FOR THE NASA COMPOSITE CRYOTANK TECHNOLOGY DEMONSTRATION PROJECT
}

\author{
Theodore F. Johnson ${ }^{1}$, David W. Sleight ${ }^{2}$, and Robert A. Martin ${ }^{3}$ \\ NASA Langley Research Center, Hampton, VA, 23681
}

\begin{abstract}
A description of the Phase I structures and design work of the Composite Cryotank Technology Demonstration (CCTD) Project is in this paper. The goal of the CCTD Project in the Game Changing Development (GCD) Program is to design and build a composite liquid-hydrogen cryogenic tank that can save $30 \%$ in weight and $25 \%$ in cost compared to state-of-the-art aluminum metallic cryogenic tank technology when the wetted composite skin wall is at an allowable strain of 5000 $\mu$ in/in. Three Industry teams developed composite cryogenic tank concepts that are compared for weight to an aluminum-lithium (Al-Li) cryogenic tank designed by NASA in Phase I of the CCTD Project. The requirements used to design all of the cryogenic tanks in Phase I will be discussed and the resulting designs, analyses, and weight of the concepts developed by NASA and Industry will be reviewed and compared.
\end{abstract}

\section{Introduction}

$\mathrm{N}^{\mathrm{s}}$ ASA is exploring advanced composite materials and processes to reduce the overall cost and weight of liquid hydrogen $\left(\mathrm{LH}_{2}\right)$ cryogenic tanks, henceforth called cryotanks, while maintaining the reliability of existing designs ${ }^{1}$. The Composite Cryotank Technology Demonstration Project (CCTD) is part of the Space Technology Program and the Game Changing Development (GCD) Program for NASA. The GCD Program focuses on maturing advanced space technologies that may lead to entirely new approaches for future Agency space missions and solutions to significant national needs. GCD projects are intended to be capability-oriented and differ from traditional research and development methods that advance discipline or core knowledge. The goal of the planned GCD Program is to mature technologies in preparation for potential system level flight demonstrations through significant ground-based testing and/or laboratory experimentation.

NASA and four Industry partners (ATK, Boeing, Lockheed Martin, and Northrop Grumman) participated in Phase I of the CCTD Project ${ }^{1}$ during fiscal year 2011 to develop conceptual designs for a $10-\mathrm{m}$ diameter composite cryotank with a goal of $25 \%$ cost savings and $30 \%$ weight reductions from current state-of-the-art aluminum metallic cryotank using 2195-T8 aluminum-lithium alloy (Al-Li). These designs included material trades and structural loads analyses, as well as manufacturing trades, autoclave versus out-of-autoclave (OoA) composite options, tooling, manufacturing and facilities, and inspection and repair. Results from these studies identified critical features and high-risk issues associated with large composite cryotanks.

NASA will work with Industry in Phase II to design, manufacture, and test a composite cryotank that incorporates the design features and strain levels that are applicable to designs up to 8.4-m in diameter. Designing and testing features applicable to an 8.4-m design ensure that the developed technologies encompass the possible size range of future heavy lift vehicles. NASA has selected a 5.5-m diameter test article for Phase II so Industry can produce and test this size tank with existing infrastructure, thereby greatly reducing the budget requirements associated with a full-scale test program. A 5.5-m diameter cryotank is of sufficient scale (i.e. similar in size to the existing Evolved Expendable Launch Vehicles

\footnotetext{
${ }^{1}$ Assistant Branch Head, Structural and Thermal Systems Branch, MS 431, AIAA Senior Member.

${ }^{2}$ Aerospace Engineer, Durability and Damage Tolerance Branch, MS 188E, AIAA Senior Member.

${ }^{3}$ Aerospace Engineer, Mechanical Systems Branch, MS 432.
} 
[EELVs]) to help identify and reduce risks associated with scale-up (e.g., cost, schedule, manufacturing, and inspection).

The development and demonstrations outlined in the CCDT Program are based on a foundation of progress in the aerospace industry over the last 20 years. Several research programs ${ }^{1}$, shown in Figure 1 have fabricated and tested composite LH2 tanks including DC-XA (circa 1994), X-33 (c. 1999) and the Space Launch Initiative (SLI) Composite Cryotank Program (c. 2006). The goal of the CCTD Project is to advance the state-the-art for composite cryotanks for future launch vehicle programs. In this paper, the Phase I activities for structural design and analysis of a 10-m diameter composite cryotank by NASA and the Industry partners will be documented. The details of the design and analyses results will also be documented in this paper.

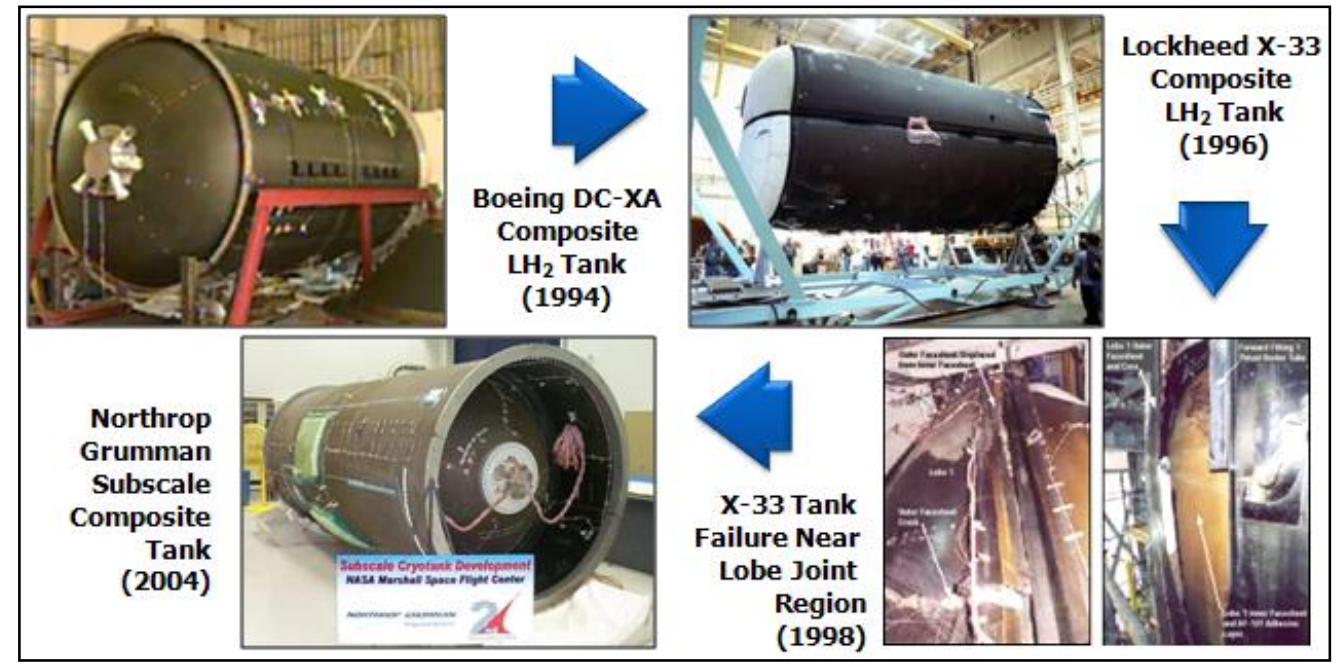

Figure 1. Development Progress of Composite $\mathrm{LH}_{2}$ Cryotanks for Launch Vehicles

\section{Structures and Designs}

The NASA team developed a 33-ft (10-m) diameter metallic aluminum alloy cryotank concept for comparison to a composite with the same overall dimensions. Industry used the metallic cryotank design to develop cost models for fabrication and weight comparison. There were three Industry IM7/977-2 composite concepts: Boeing fluted core, Lockheed-Martin externally stiffened, and Northrop Grumman sandwich. The designs developed by NASA and Industry partners will be discussed and presented.

\section{A. Requirements and Loads}

The NASA team worked with the Industry partners to develop a base set of requirements for the structural designs and testing of a composite cryotank. The collaborative effort at requirement definition was considered valuable by all participants. Combining the breadth of experience from both NASA and the Industry teammates during the formulation process resulted in a set of requirements that were more comprehensive and inclusive than if the requirements had been chosen by a single party. A sample of the design requirements is shown in Figure 2.

The composite tank had an integral skirt that extended beyond the Y-joint of the tank. The extensions were added to minimize temperature effects (coefficient of thermal expansion [CTE] mismatch) on the metallic ring used to mate the composite cryotank to an adjacent component. Typical metallic cryotanks end at the Y-joint with an interface flange or kick ring for mating to adjacent components. The loads and factors of safety for the composite and metallic tank are listed in Table 1. The loads, length, and volume were based on a 33-ft (10-m) diameter Ares V Earth Departure Stage (EDS) $\mathrm{LH}_{2}$ tank. Factors of safety were specified from CxP $70135^{2}$ and NASA STD-5001A ${ }^{3}$. A common global shell buckling knockdown factor was used for all concepts, regardless of the wall configuration or material. The local crippling knockdown factor was 1.0 based on previous design studies ${ }^{4}$. A maximum lamina strain of $5000 \mu$ in/in was specified by the project. The maximum compression strain, $3300 \mu \mathrm{in} / \mathrm{in}$, was based on the Poisson's 
effect of bi-directional loading. All of the Phase I concepts were required to use Government furnished information (GFI) IM7/977-2 lamina material property. A maximum stabilization pressure of 20 psi was selected as the residual pressure in the cryotank just before vehicle destruction. The allowable permeation rate of $10^{-3} \mathrm{scc} / \mathrm{sec} / \mathrm{sq}$-in was from Robinson et. al. ${ }^{5}$. A zero pressure was set for a pressure failure during a launch. Egress and ingress of the cryotank would be through a 30-in diameter access opening ${ }^{6}$.

\section{Design Requirements}

- $\quad$ Diameter $=394$ in

- $\quad$ Volume $=22,400 \mathrm{ft}^{3}$

- $\quad$ Max Design Pressure $=46.2$ psi

- $\quad$ NASA-defined external loads (axial, shear, and moment)

- Factor of Safety

$\circ \quad$ Tank acreage $=1.5$

- $\quad$ Composite joint $=2.0$

- Material IM7/977-2 Gr/Ep

- Limit lamina tensile strain $=5000 \mu$ in/in

- $\quad$ Two 30-inch diameter openings at sump forward dome

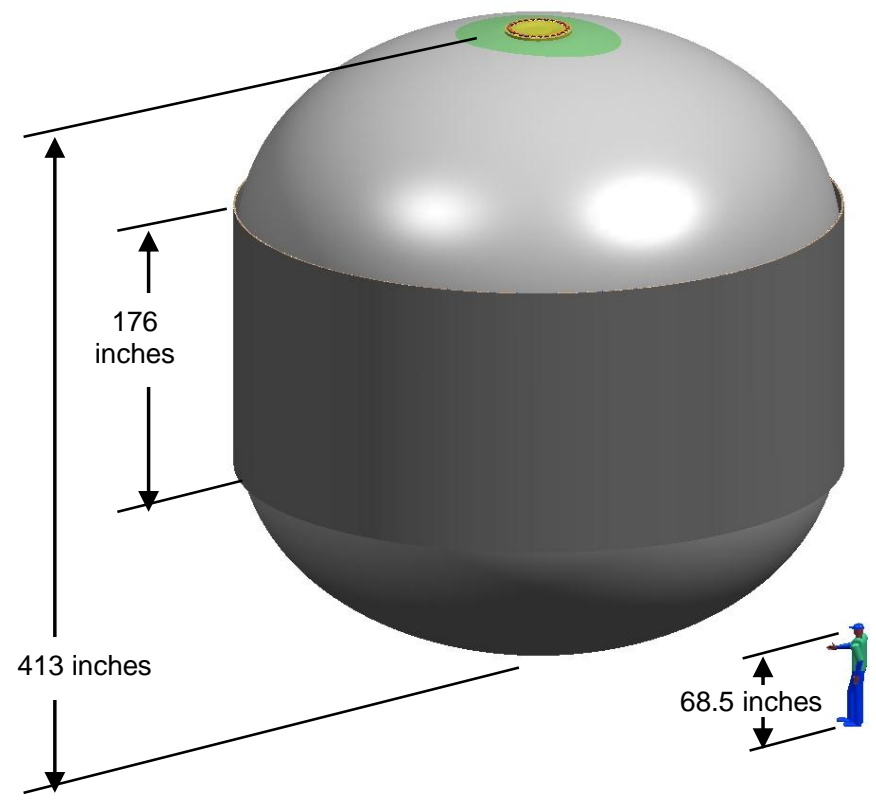

Figure 2. NASA Reference Cryotank Geometry and High Level Requirements

Table 1. Loads Cases for a 33-ft (10-m) Diameter Composite and Metallic Cryotank.

\begin{tabular}{|c|c|c|c|c|c|c|}
\hline $\begin{array}{c}\text { Load } \\
\text { Case } \\
\text { No. }\end{array}$ & $\begin{array}{c}\text { Load Case } \\
\text { Name }\end{array}$ & $\begin{array}{c}\text { Axial } \\
\text { Load } \\
\text { (lbs) }\end{array}$ & $\begin{array}{c}\text { Shear } \\
\text { Load } \\
\text { (lbs) }\end{array}$ & $\begin{array}{c}\text { Moment } \\
\text { (in-lbs) }\end{array}$ & $\begin{array}{c}\text { Internal } \\
\text { Pressure } \\
\text { (psi) }\end{array}$ & Factors of Safety \\
\hline 1 & Proof & - & - & - & $46.2^{*}$ & $\begin{array}{c}1.0 \text { Minimum } \\
{[1.0 \text { Minimum }]^{\infty}}\end{array}$ \\
\hline 2 & $\begin{array}{c}\text { Max. } \\
\text { Compression }\end{array}$ & $-\mathrm{F}_{\mathrm{x}}$ & $\mathrm{F}_{\text {shear }}$ & $\begin{array}{c}\mathrm{M}_{\mathrm{z}} \\
{\left[\mathrm{M}_{\mathrm{z}} \mathrm{x} 1.438\right]}\end{array}$ & $20^{\ddagger}$ & $\begin{array}{c}1.5 \text { Uniform } \\
2.0 \text { Discontinuities } \\
{[1.1 \text { Yield] }} \\
{[1.4 \text { Ultimate }]}\end{array}$ \\
\hline 3 & Max. Tension & $-\mathrm{F}_{\mathrm{x}}$ & $\mathrm{F}_{\text {shear }}$ & $\begin{array}{c}\mathrm{M}_{\mathrm{z}} \\
{\left[\mathrm{M}_{\mathrm{z}} \mathrm{x} 1.438\right]}\end{array}$ & $46.2^{*}$ & $\begin{array}{c}1.5 \text { Uniform } \\
2.0 \text { Discontinuities } \\
{[1.1 \text { Yield }]} \\
{[1.4 \text { Ultimate }]}\end{array}$ \\
\hline 4 & $\begin{array}{c}\text { Internal } \\
\text { Pressure } \\
\text { Failure }\end{array}$ & $-\mathrm{F}_{\mathrm{x}}$ & $\mathrm{F}_{\text {shear }}$ & $\begin{array}{c}\mathrm{M}_{\mathrm{z}} \\
{\left[\mathrm{M}_{\mathrm{z}} \mathrm{x} 1.438\right]}\end{array}$ & 0 & $\begin{array}{c}1.00 \text { on all Margins } \\
{[1.0 \text { Ultimate }]}\end{array}$ \\
\hline
\end{tabular}

Note: Data in [ ] are for metallic tanks

$\infty$ Proof load enchantment factor of 1.05

* Factored pressure is 0.955 for cryogenic enhancement

$\$$ Factored pressure is 1.0 to reduce pressure stabilization

** Damaged state

Bolt fitting factor was 0.8

The Y-joint, dome, and barrel sections were integral in a composite design. The 60 -inch extension structures shown in Figure 3A and Figure 3B are additions to a metallic cryotank for comparison with the composite cryotank. All three composite designs from the Industry partners were 176-in in length from Yjoint to Y-joint to obtain comparable masses. Since 60-in extensions were added, the component loads had 
to be adjusted for the increased distance in application of load. The moment loads were adjusted to achieve the same effective line load at the bottom of the barrel section of the metallic tank or barrel section depicted in Figure 3A.

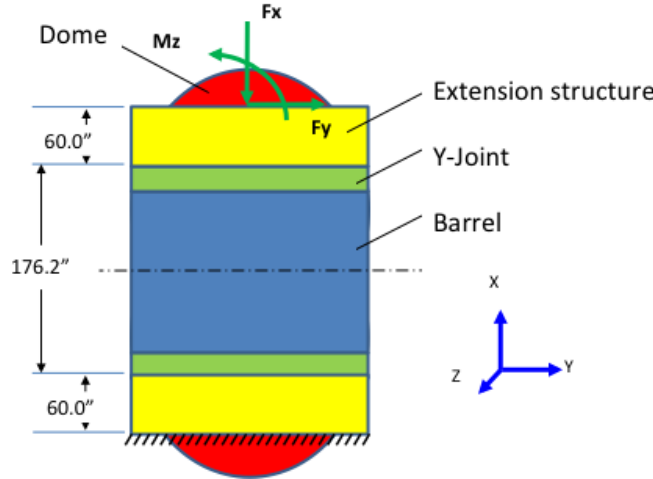

A.)

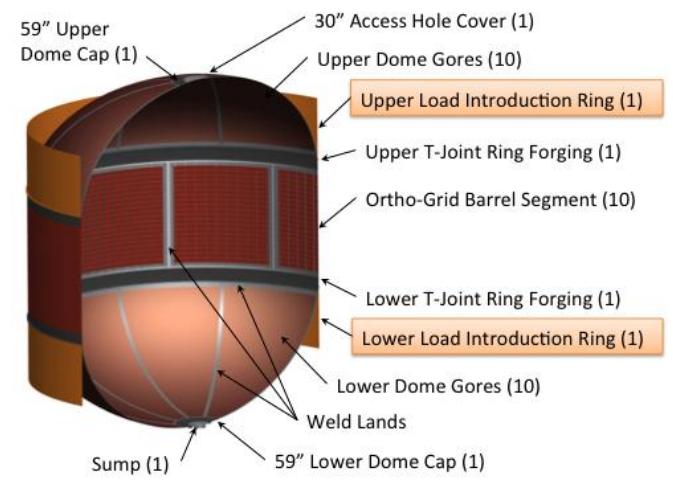

B.)

Figure 3. A.) Analysis Boundary Conditions and Load Application. B.) NASA Metallic Design Concept with a 59-Inch Diameter Dome Cap.

\section{B. NASA Al-Li Metallic Concept}

A metallic 33-ft (10-m) diameter cryotank concept was developed using Space Shuttle External Tank and Constellation Ares I $\mathrm{LH}_{2}$ cryotank design methods. The tank would be assembled using friction stir welding and would require four-inch wide weld lands for inspection of the welds. Welds were staggered to prevent crack propagation through the welds. The maximum usable stock size of available 2195-T8 Al-Li alloy sheets is 246 -in long by 130 -in wide by 1.65 -in thick. This restriction leads to a ten-gore segment dome design. The sized orthogrid barrel for this conceptual upper stage cryotank design was 1.58 -in thick and therefore not restricted by the available Al-Li stock size. The available stock size did however lead the design team to switch to a 2219-T87 aluminum alloy for the thicker dome caps, access cover, sump, and " $T$ " joints. The initial metallic cryotank design is shown in Figure 3B with a 59-inch diameter dome cap.

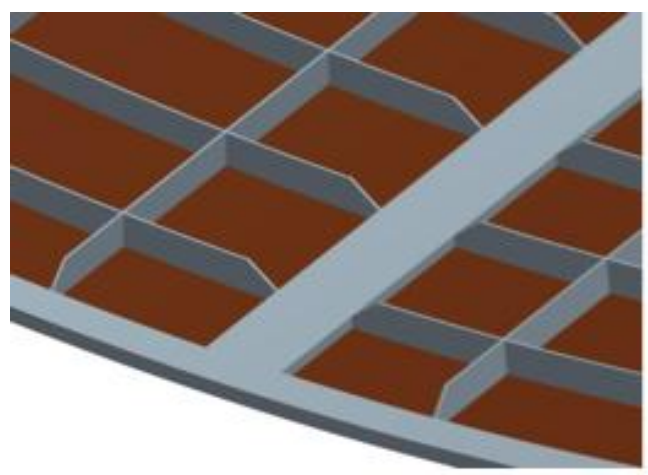

A.)

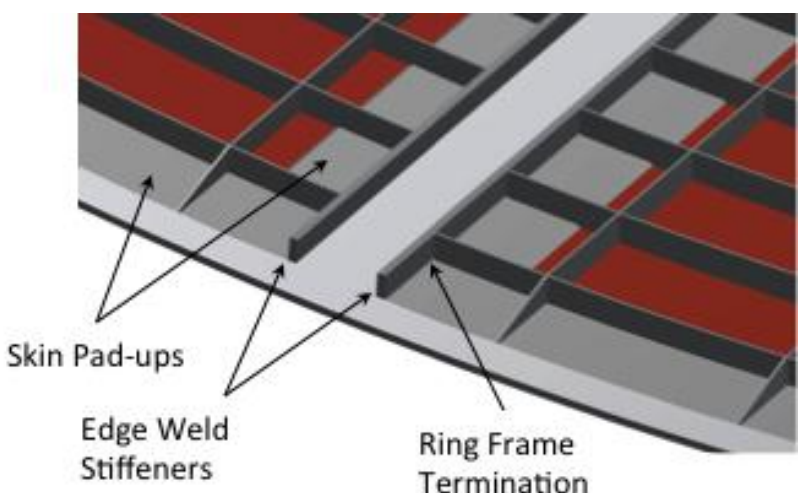

B.)

Figure 4. NASA Al-Li Concept Barrel Weld Lands A.) Original Design and B.) Modified for a Reduction in Weight.

One of the primary weight drivers was the barrel section to barrel section weld land weight. Welds and weld lands comprised $25 \%$ of the total mass. Sizing analyses called for a thick weld land to counteract the moment induced from the transition from orthogrid to a flat plate as seen in Figure 4A. As one added more mass to the weld land, the weld land drew more axial compression load and had to be resized to prevent buckling in the weld land. Additional moment constraints were added in the model to reduce bending but the results were not consistent with other technical readiness level ${ }^{8}$ (TRL) 9 designs. A high-fidelity model was created with weld steps, but high mass welds still resulted. Using results by Thornburgh and 
Hilburger ${ }^{7}$, an additional orthogrid rib was added to the sides of the barrel weld lands as shown in Figure 4B, which resulted in the development of lower mass barrel sections.

The design shown in Figure 3B represents a TRL 9 metallic cryotank design with a final Phase I total mass of 10,925-lbs. An eigenvalue plot for the metallic cryotank design is shown in Figure 5. Spun form domes $^{9,10}$ could be used to reduce weight by reducing or eliminating gore panels in the domes. Three domes at different TRL levels and associated weights are shown in Figure 6. The TRL 9 dome is the baseline used in design shown in Figure 3B. Even though a 16-ft. diameter spun form dome cap is used in the TRL 6 design, ten gore panels are used in the dome. The TRL 3 dome is a full $33-\mathrm{ft}$ (10-m) diameter spun form dome. A significant mass savings does not materialize with the use of spun formed domes, but there may be a significant cost savings with reduced touch labor and tooling.

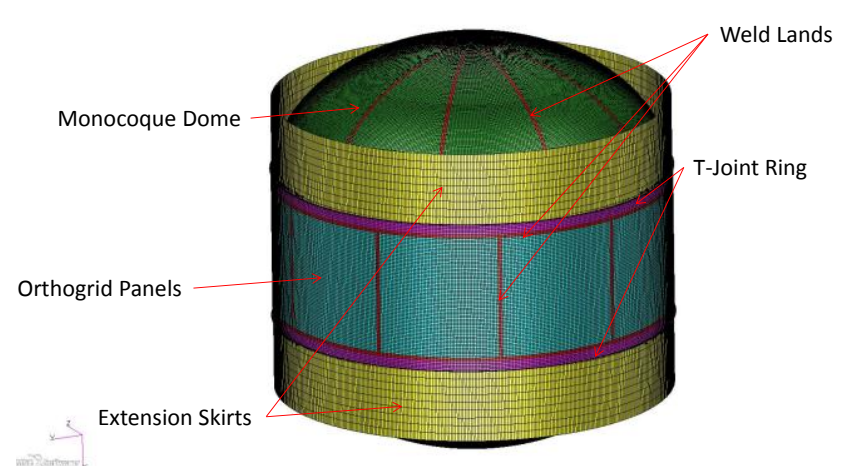

A.)

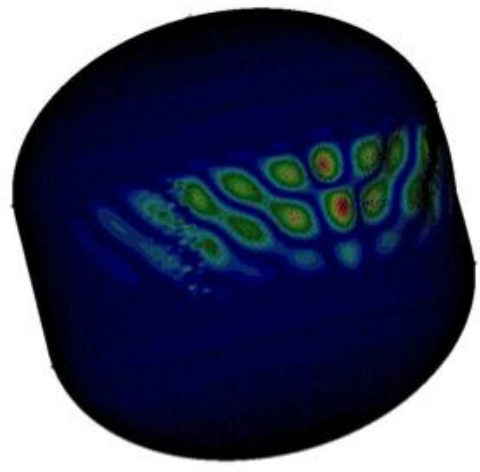

B.)

Figure 5. NASA Al-Li Concept A.) Finite Element Model, and B.) Eigenvalue Plot of Load Case 4, Unpressurized Flight Failure.

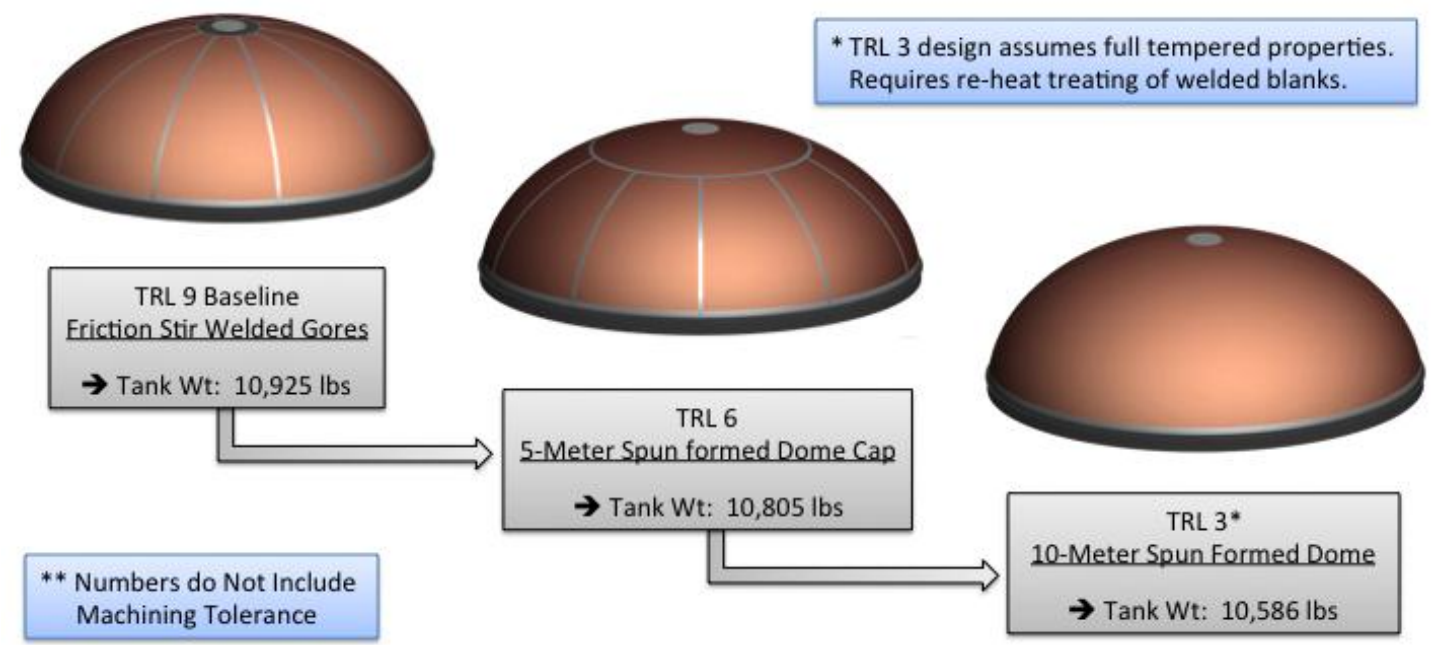

Figure 6. Spun Formed Domes at TRLs of 9, 6, and 3 with the Final Total Weight for the NASA Al-Li Concepts.

\section{Boeing Composite Fluted-Core Concept}

Boeing selected to use a composite fluted-core design based on their history in developing composite cryotanks for launch vehicles. An ultimate load case with axial flight loads and an unpressurized tank in the CCTD requirements drove the Boeing pressure vessel cylinder wall to a stiffened cylinder wall, rather than a monocoque design.

Boeing considered other tank design such as stiffened concepts but was never able to show a positive margin on the alternate stringer-to-skin bondline for very large cryotanks. Boeing noted that a sandwich construction or overwrap had the desirable property of loading the core compressively, which increases the 
shear capability of the joint as illustrated in Ref. 11. Preliminary analytical studies indicated that ventable fluted core sandwich, with canted flute walls to stiffen the shell in the direction normal to the flute axis, was a construction that could have positive margins. Boeing also selected to eliminate utilizing a bellyband joint by using a breakdown tool to form the primary pressure vessel.

A cross-section of the Boeing fluted-core sandwich wall-core concept and cross-sections of the fluted core are shown in Figure 7. A hybrid dome was selected by Boeing to minimize the discontinuity stress at the dome to barrel interface. The final monocoque dome shape was determined by interpolation and bracketed by Cassinian and elliptical dome shapes. Six half thickness plies, 0.0025 -in, were at the center of all $\mathrm{LH}_{2}$ wetted laminates to prevent hydrogen permeation ${ }^{1}$.

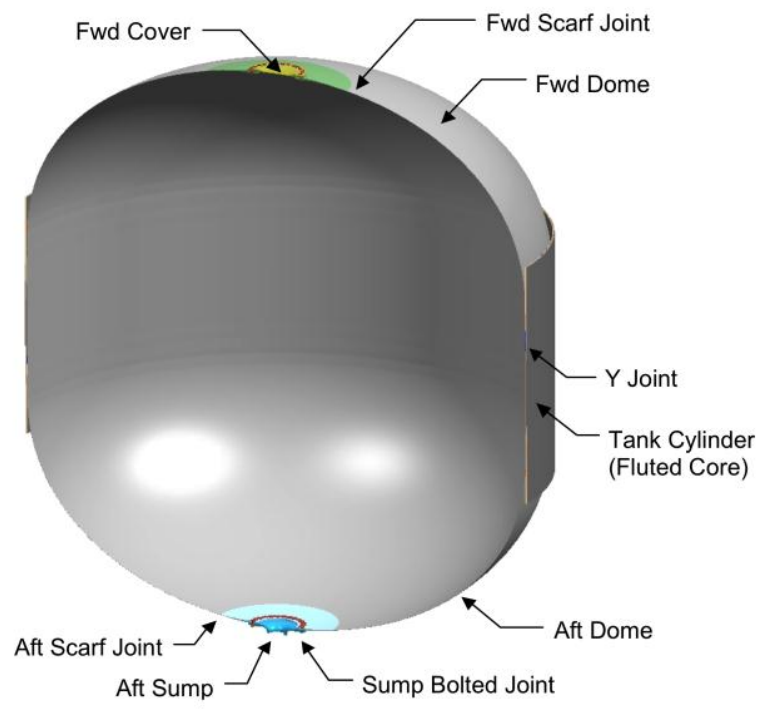

A.)

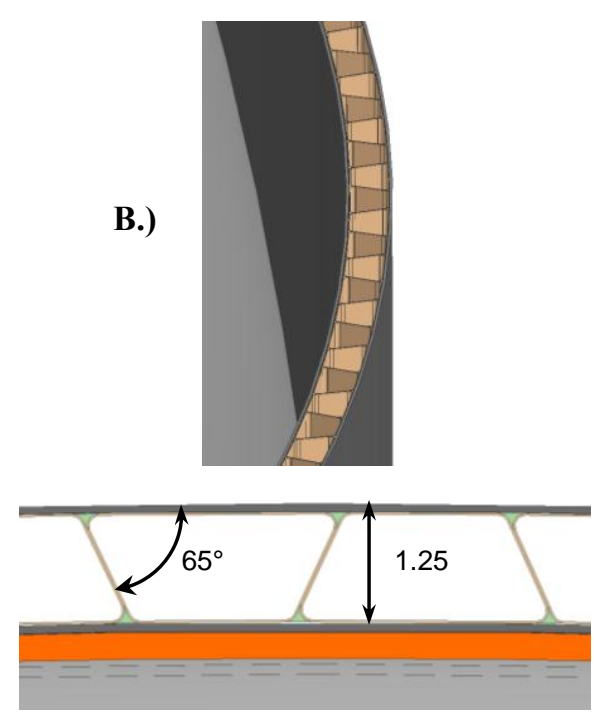

C.)

Figure 7. Boeing Fluted Core Sandwich Wall Concept A.) Cross-Section of the Cryotank, B.) Isometric Edge View of the Fluted Core, C.) Edge Cross-Section View of the Fluted Core. Dimensions are in Inches.

The global stress model was analyzed for two critical loading cases, load case 1 and load case 3 in Table 1. The strains in the tank domes are driven by internal pressure, so for both load cases, the maximum dome strains were the same $4984 \mu \mathrm{in} / \mathrm{in}$ on the forward dome and $4739 \mu \mathrm{in} / \mathrm{in}$ on the aft dome. The cylinder maximum strain for load case 1 is $4064 \mu \mathrm{in} / \mathrm{in}$. For load case 3, the cylinder maximum strain is $4570 \mu \mathrm{in} / \mathrm{in}$ on the outer mold line (OML) facesheet and $4444 \mu \mathrm{in} / \mathrm{in}$ on the inner mold line (IML) facesheet. An eigenvalue plot for the barrel section is shown in Figure 8 with an eigenvalue of 2.97 and a margin of safety of 0.94. Additional plies were added to the skirts to shift buckling to the barrel with higher eigenvalue. There was a high peak peel stress at the tip of the Y-joint on the dome. Boeing determined that a softening strip was required to distribute the shear load along the dome to reduce the peak peel stress at the end of the bond line. The contribution of the softening strip to the reduction of shear stress is shown in Figure 9. The final mass of the Boeing concept o ver the 176-in length with both domes was 6696-lbs.

\section{E. Lockheed-Martin Composite Externally-Stiffened Concept}

Lockheed-Martin decided to use a stiffened shell approach based on heritage cryotank with NASA at the Michoud Assembly Facility (MAF). Lockheed-Martin concluded that a monocoque shell with external stiffeners would be more damage tolerant with a thicker shell compared to sandwich-type wall constructions. The shell would be built on a breakdown tool that would be extracted from the dome openings. The external stiffeners would be fabricated using a Lockheed-Martin pi preform technology. The Lockheed-Martin concept and pi preform hat stiffener are shown in Figure 10. 


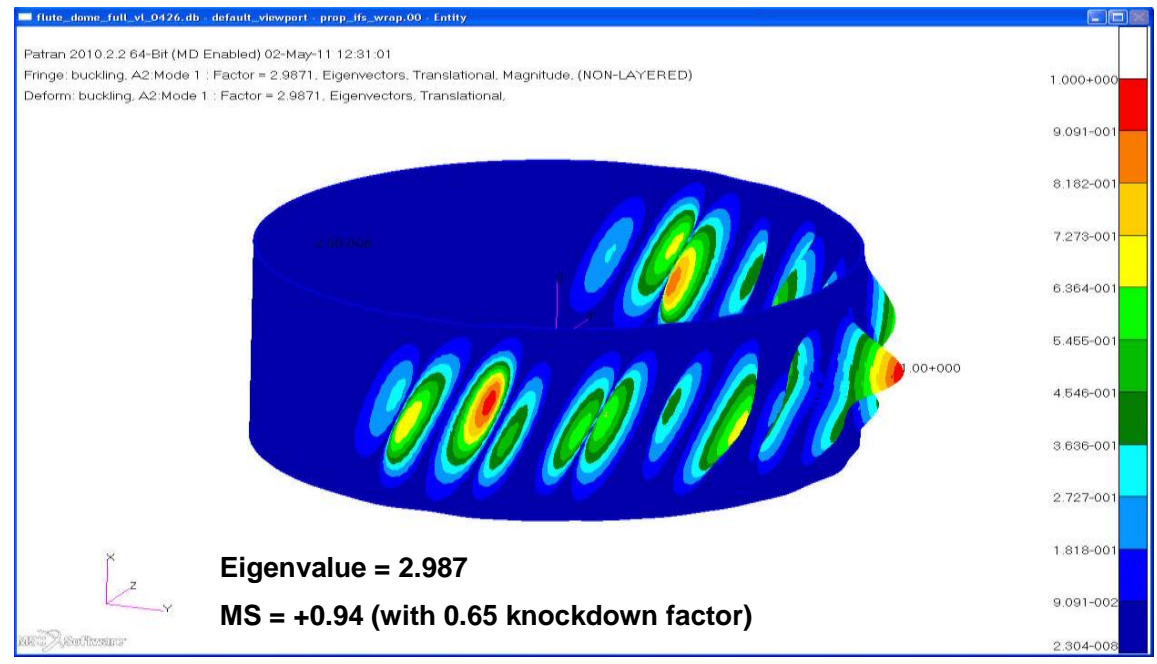

Figure 8. Case 4 Eigenvalue Plot for the Boeing Fluted Core Sandwich Concept.

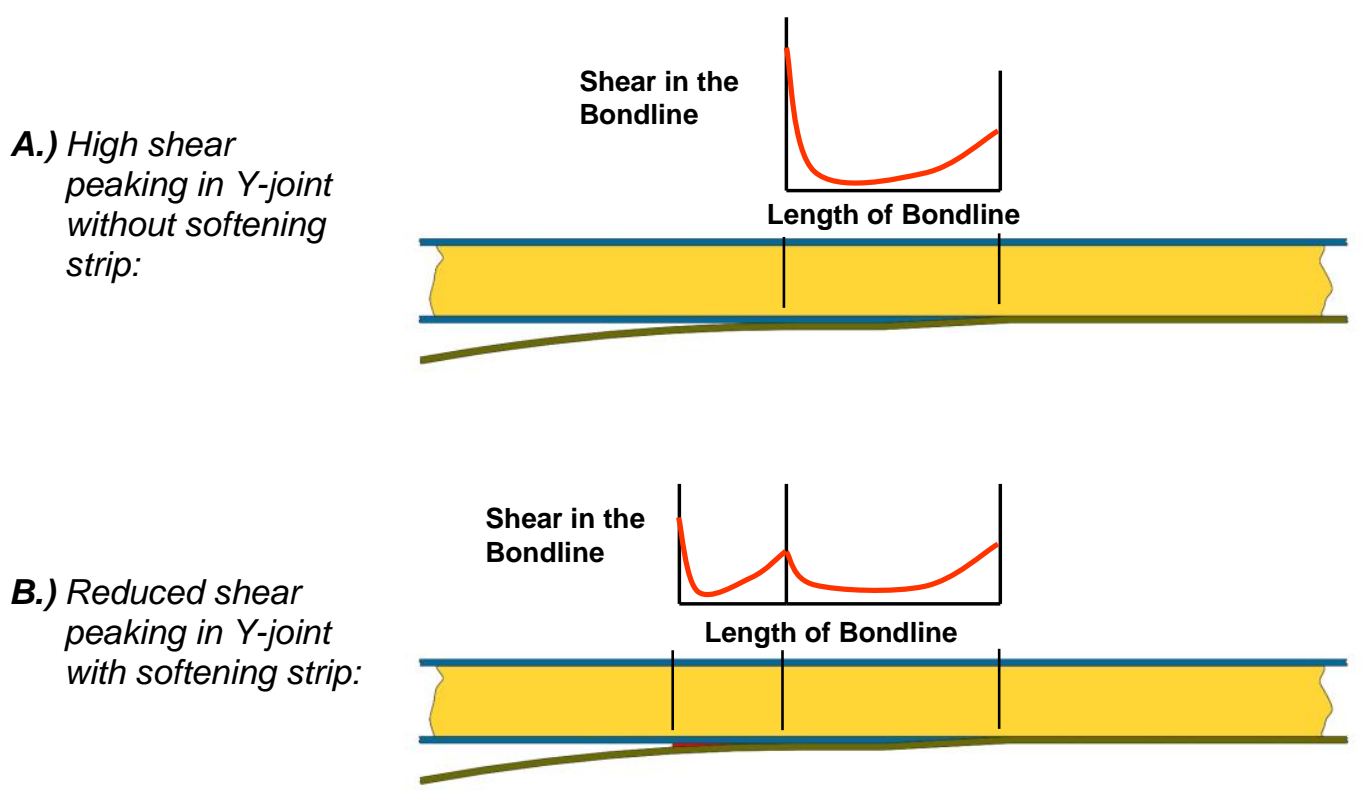

Figure 9. Shear Stress Distribution in the Bondline on the Dome for the Boeing Fluted Core Sandwich Concept Y-joint A.) Without a Softening Strip, B.) With a Softening Strip.

The monocoque domes of the tank had a 0.76 elliptical ratio to combine low hoop stress under pressure with a compact dome dimension that reduced overall tank acreage. The Y-joint was not a significant issue for Lockheed-Martin since an advantage of the stiffened skin concept was that their concept was a tank within a tube (barrel overwrap and skirt) design where Lockheed-Martin analyzed that the bondline only had to transfer half of the mechanical load through the adhesive at the Y-joint. A schematic of the Lockheed-Martin load transfer at the Y-joint is depicted in Figure 11.

Initial designs employed just a monocoque shell but incurred a thick skin penalty due to stability requirements. A hoop and axial blade stiffener design was considered but the manufacturing complexity was too large compare to other designs. An axial blade stiffener design was designated as the baseline, but had 110 stiffeners, spaced at $11.3 \mathrm{in}$., would be required. An alternate axial hat stiffener design was also considered. The hat stiffened design would require only 76 stiffeners spaced at $16.3 \mathrm{in}$. apart.

Both the blade stiffener concept and the hat stiffened concept were analyzed and sized. Each concept had strain of $5000 \mu \mathrm{in} / \mathrm{in}$ for flight tension. The stability case, load case 4 , sized the height of the stiffeners. 
The eigenvalues for the zero pressure case, load case 4, were 1.56 for the blade stiffened concept and 1.67 for the hat stiffened concept. Eigenvalue plots for load cases 2 and 4 are in Figure 12 for the hat stiffened concept. The weight of the blade stiffened and hat stiffened concepts were 7293-lbs. and 6573-lbs., respectively. The hat stiffener concept was selected as the final concept for Lockheed-Martin.

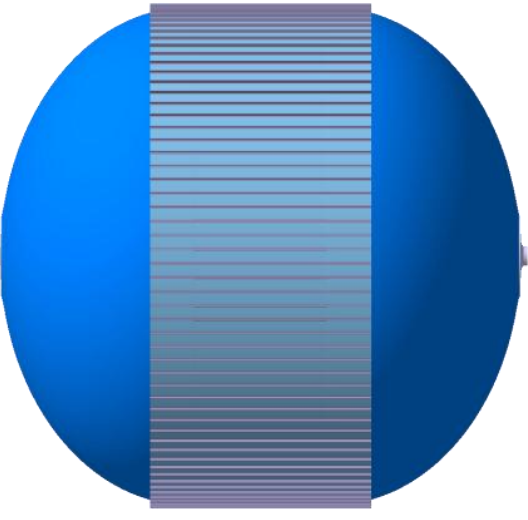

A.)

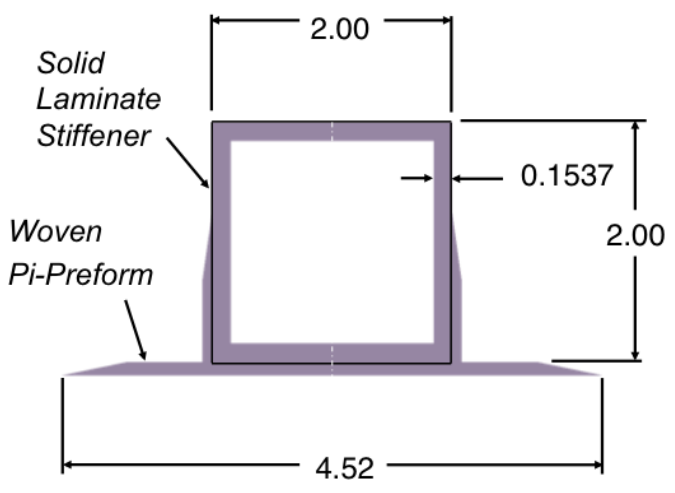

B.)

Figure 10. The Lockheed-Martin A.) Composite Stiffened Concept B.) Pi Preform Hat Stiffener. Dimensions are in Inches.

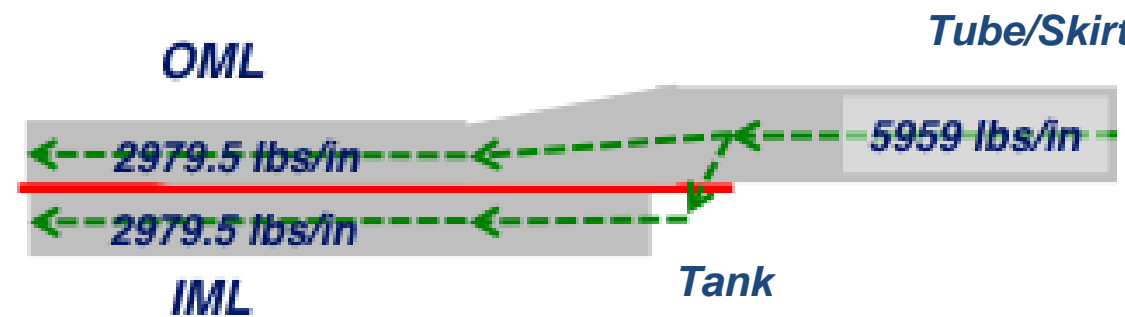

Figure 11. Load Transfer in Lockheed-Martin Y-Joint.

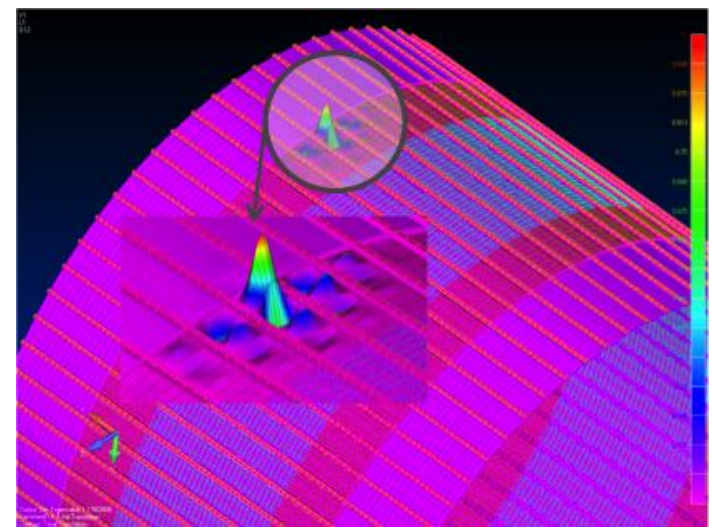

A.)

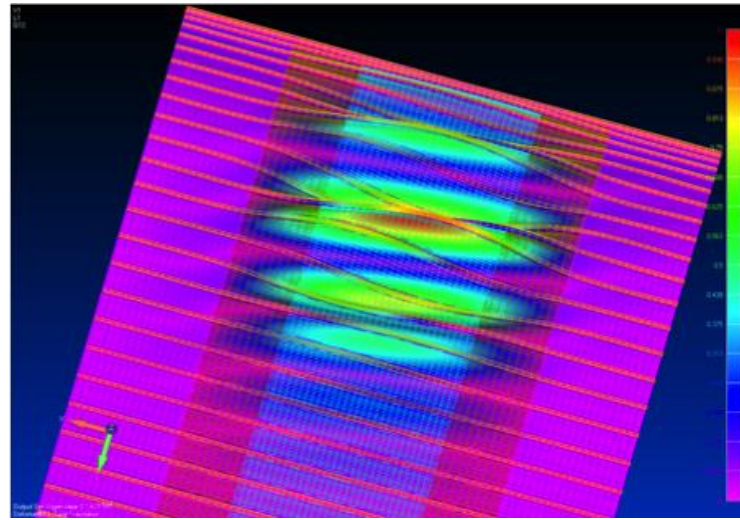

B.)

Figure 12. Eigenvalue Plots for the Lockheed-Martin Hat Stiffened Concept A.) Load Case 2, Eigenvalue $=1.56$, B. $)$ Load Case 4, Eigenvalue $=1.67$.

\section{G. Northrop Grumman Composite Sandwich Concept}

The Northrop Grumman composite sandwich tank concept used a perforated honeycomb core in a dual role to reduce weight, where the honeycomb core between the two structural facesheets served as a 
structural stiffening member and cryogenic insulation. The dual role operation was achieved by attaching a vacuum port into the honeycomb core plenum and evacuating the air in the core while on the launch pad or during testing. The evacuated core plenum would turn the tank wall into a vacuum jacket. The $3 \mathrm{pcf}$ phenolic-aramid honeycomb core ribbon has a very low conductivity through the thickness ${ }^{12}$. This approach minimizes weight, since the same material that stiffens the tank wall from buckling also serves as a cryogenic insulation. A schematic of the Northrop Grumman composite sandwich tank concept and the Y-joint are shown in Figure 13. The total weight of the Northrop Grumman composite honeycomb sandwich concept was 6252-lbs.

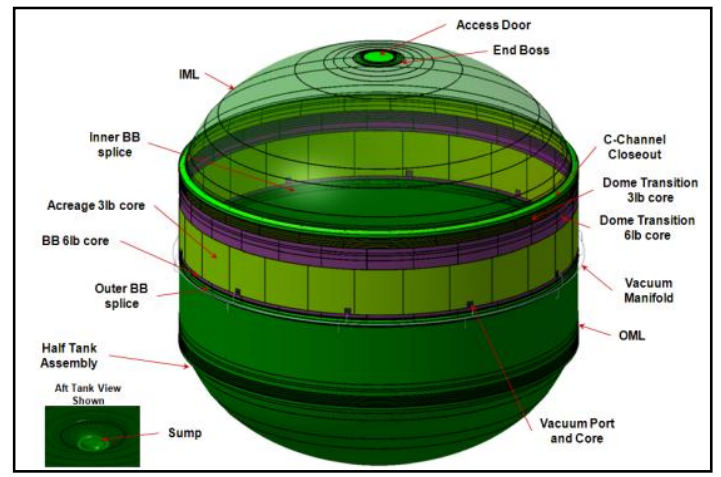

A.)

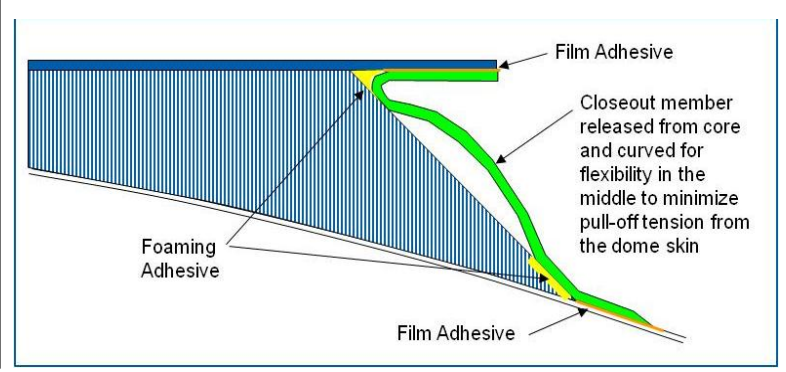

B.)

Figure 13. Northrop Grumman Composite Honeycomb Sandwich Concept A) Overall Concept B) YJoint Cross-Section

The tank is produced in two half sections, and joined via a central circumferential belly-band joint. The core increases in depth just beyond the dome tangency to facilitate effective load transfer and shear softening in the Y-joint region. The dome is of solid laminate construction (monocoque). The IML facesheet is comprised of 0.0026 -in thick tape lamina to reduce hydrogen permeability ${ }^{1}$. The OML uses 0.0052 -in thick tape lamina only.

Northrop Grumman selected the Y-joint concept, shown in Figure 13, which features a thick solid laminate at the skirt interface area with a deep honeycomb core. There is a C-channel closeout to seal the perforated core plenum of the barrel of the tank. High local flatwise tension loads necessitated the creation of a tension-relief arc in the C-channel.

Analysis results of the cryotank indicated that there are positive margins for the domes and barrels. A maximum strain of $4687 \mu \mathrm{in} / \mathrm{in}$ would occur in the dome region just above the Y-joint. A plot of the buckling case shown in Figure 14A indicates that buckling occurs in the $\mathrm{Y}$-joint region with positive margin of $3 \%$ and an eigenvalue of 1.7. A classic buckling pattern was not achieved in the barrel section of the cryotank until the $6^{\text {th }}$ buckling mode shown in Figure 14B, where additional plies had to be added to the skirt to reduce bending in the Y-joint and to drive buckling into the cryotank barrel.

\section{Discussion}

Four cryotanks were documented in this paper, one metallic cryotank concept and three composite cryotank concepts. The NASA Al-Li metallic cryotank concept used an advanced weld land design to join the orthogrid panels to reduce weight. Spun formed domes were not employed since they did not reduce weight but could potentially significantly reduced costs from touch labor and tooling. Boeing had a fluted core concept that would be built on a breakdown tool and would not require a cryotank joint. LockheedMartin selected a square pi preform hat stiffener stiffened design that would also be built on a breakdown tool. The Northrop Grumman design was a honeycomb core sandwich design that would be built in hemispheres and joined with a belly-band joint. The honeycomb core in the Northrop Grumman design would be used to insulate the tank if the air in the honeycomb core was evacuated.

The NASA Al-Li metallic cryotank concept was compared to three composite cryotank concepts from Industry. A plot of the weight comparison for the four concepts is shown in Figure 15. The red line at 7248-lbs in Figure 15 represents the goal of 30\% reduction in weight from the NASA Al-Li metallic design 
Phase I weight. The three companies exceeded the reduction in weight goal with their composite designs and had designs where the laminates were at or under the $5000 \mu \mathrm{in} / \mathrm{in}$ strain limit.

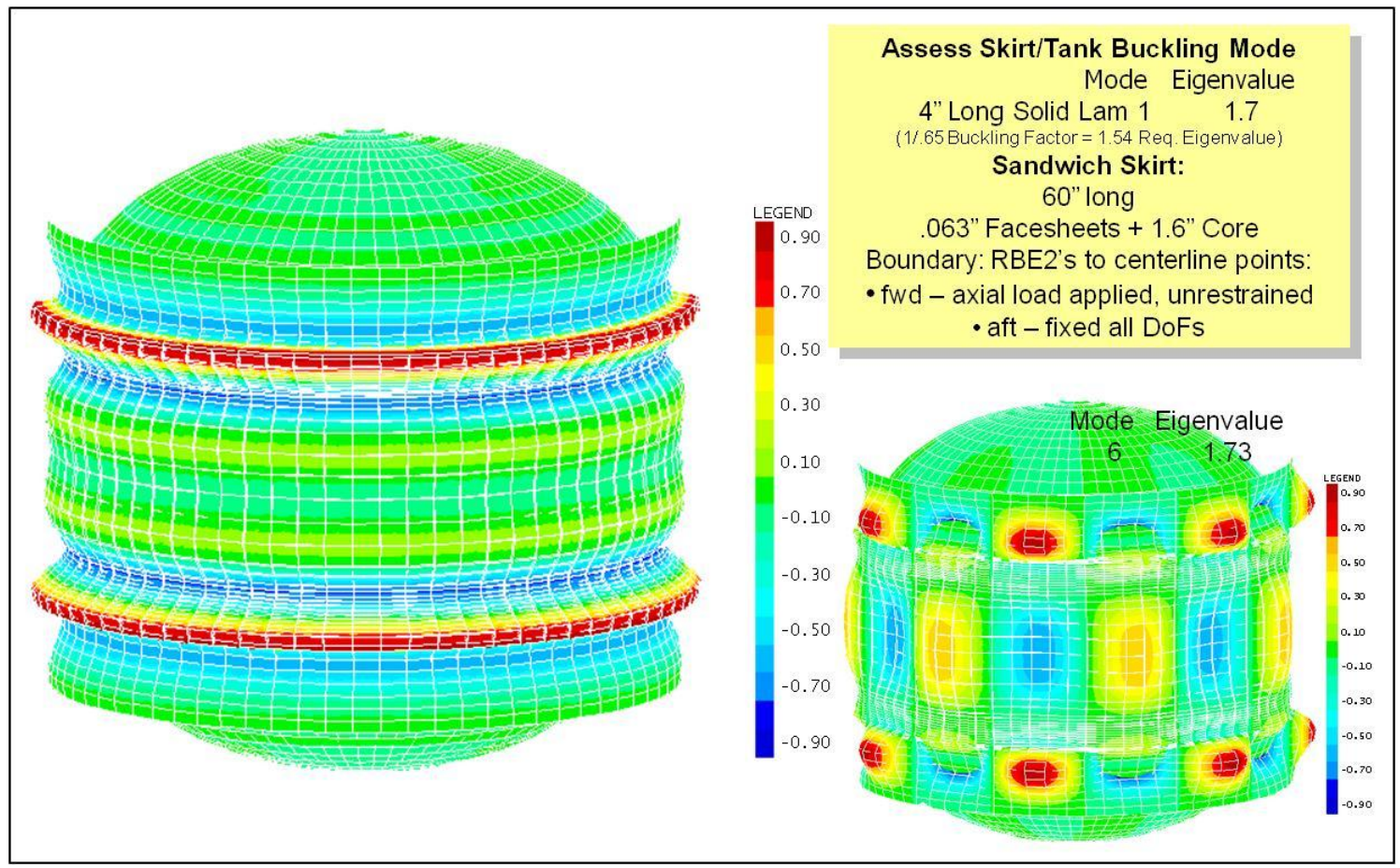

A.)

B.)

Figure 14. Eigenvalue Plots for the Northrop Grumman Composite Honeycomb Sandwich Concept A.) Mode 1 Eigenvalue = 1.7, B.) Mode 6 Eigenvalue = 1.73.

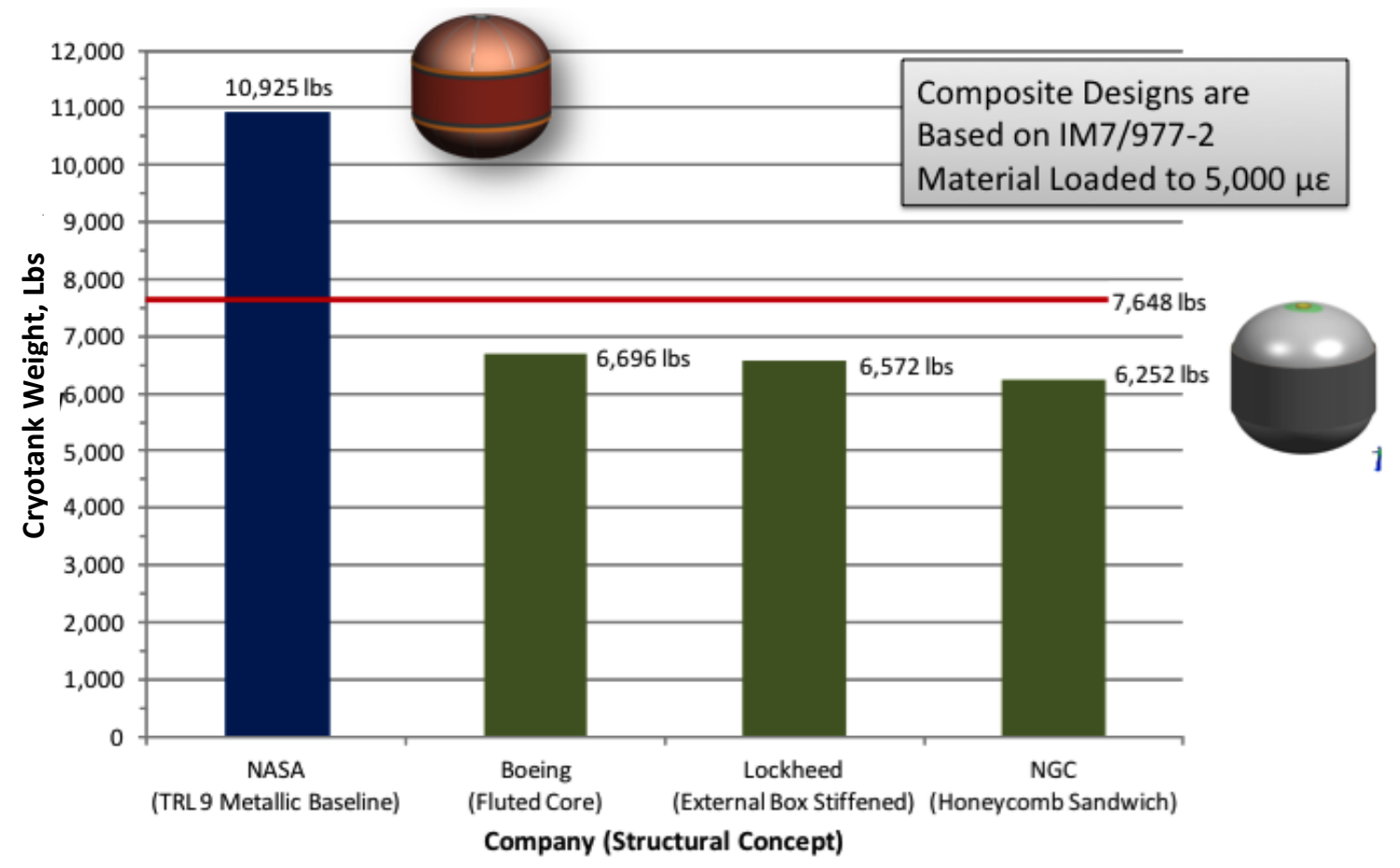

Figure 15. Comparison of the Three Industry Composite Designs to the Metallic Design from NASA 
Use of 0.0026 -in laminas ${ }^{1}$ in the IML facesheet, increased the possibility of having IML facesheets that were resistant to hydrogen permeability for Boeing and Northrop Grumman. The composite concepts from Industry had additional buckling strength capability in their designs, where the Boeing and Northrop Grumman concepts experienced the same phenomena and additional plies had to be added to the skirt to have buckling occur in the barrel of the cryotank. The Y-joint in the composite designs was problematic due to having to transfer shear load from barrel to the dome. This transfer of load caused peel to occur at the interface of the dome, barrel, and skirt. Boeing and Northrop Grumman chose to use a softening strip approach where Boeing used a soft isotropic material to transfer load while Northup Grumman used a deep honeycomb core to transfer load. Lockheed-Martin elected to use a tube-in-tube approach to transfer load to the dome without a softening medium in the Y-joint.

\section{Summary}

The objective of the CCTD Project is to advance the technologies required to develop lightweight composite cryotanks applicable to heavy-lift launch vehicles, propellant depots, and future lander systems. Success in this project will lead to cryotanks that are more than $30 \%$ lighter and cost $25 \%$ less to manufacture compared to the current state-of-the-art metallic tanks.

Three stiffened composite-cryotank concepts were developed by Industry partners and compared to a NASA-developed Al-Li metallic cryotank. All three composite concepts exceeded the $30 \%$ weight reductions desired by the CCTD Project when compared to the metallic cryotank. The cryotanks were designed to exceed the proscribed buckling strength and have an allowable strain close to $5000 \mu \mathrm{in} / \mathrm{in}$. Use of 0.0026-in laminas in the IML facesheet increased the possibility of having IML facesheets that were resistant to hydrogen permeability for the Boeing and Northrop Grumman designs.

\section{References}

1. Vickers, J.H., Fikes, J., Jackson, J.R., Johnson, T.F., Sutter, J. K., and Martin, R. A., "NASA Composite Cryotank Technology Demonstration: Overview", SAMPE 2012 Conference, Baltimore, MD, 2012.

2. Anon., "Constellation Program Structural Design and Verification Requirements," CxP 70135, National Aeronautics and Space Administration (NASA), Washington, DC, July 2008.

3. Anon., "Structural Design and Test Factors of Safety for Spaceflight Hardware," NASA STD-5001A, National Aeronautics and Space Administration (NASA), Washington, DC, August 2008.

4. Sleight, D., Sreekantamurthy, T., Kosareo, D., Martin, R., and Johnson, T., "Structural Design of Ares V Interstage Composite Structure," AIAA-2011-1790, 52 nd AIAA/ASME/ASCE/AHS/ASC Structures, Structural Dynamics, and Materials Conference, Denver, CO, April 2011.

5. Robinson, M.J., Eichinger, J.D., Johnson. S.E., "Hydrogen Permeability Requirements and Testing for Reusable Launch Vehicle Tanks," Proceedings of the 43rd AIAA Structures, Structural Dynamics, and Materials Conference, Denver, CO., April 22-25, 2002.

6. Anon., "Department of Defense Design Criteria Standard: Human Engineering," MIL-STD-1472F, 23 August 1999.

7. Thornburgh, R.P., Hilburger, M.W., "Longitudinal Weld Land Buckling in Compression-Loaded Orthogrid Cylinders," NASA/TM-2010-216876, ARL-TR-5121, December 2010. 7.

8. Mankins, J. C., “Technology Readiness Levels,” A White Paper, April 6, 1995.

9. Curreri, P.A., Lollar, L.F., Torres, P.D., Russell, C.K., Hoffman, E.K., Domack, M.S., Edahl, Jr., R.A., Shenoy, R.N., Cooks, R.E., and Tayon, W.A., Brewster, J., Bank, J., Pham, D., T. L, and Reinmuller, R., Steward, T. and Caratus, A., Schneider, J., "Aluminum-Lithium, Friction Stir Welded, Spun-Formed Domes for Light-Weight Cryogenic Propellant Tanks Part I: 1-Meter-Diameter Proof of Concept," NASA/TP-11-216462/Addendum, March 2011.

10. Hales, S.J., Tayon W.A., Domack, R.A., "Friction-Stir-Welded and Spin-Formed End Domes for Cryogenic Tanks," Proceedings of the 41st Structures and Mechanical Behavior Meeting during the 2012 JANNAF Annual Meeting, May, 2012.

11. L.B. Greszczuk, "Strength of Adhesives Under Combined Loading", Report MDC H2620, October 1987.

12. Johnson, T. F., Weiser, E. S., Grimsley, B. W., and Jensen, B. J., "Cryopumping in Cryogenic Insulations for a Reusable Launch Vehicle," Presented at the 48th International SAMPE Symposium and Exhibition, Long Beach, CA, May 11-15, 2003. 